\title{
High-Lift Propeller Noise Prediction for a Distributed Electric Propulsion Flight Demonstrator
}

\author{
Douglas M. Nark, Pieter G. Buning† William T. Jones $\underset{\ddagger}{\dagger}$ Joseph M. Derlaga ${ }^{\S}$ \\ NASA Langley Research Center, Hampton, VA 23681-2199, U.S.A
}

\begin{abstract}
Over the past several years, the use of electric propulsion technologies within aircraft design has received increased attention. The characteristics of electric propulsion systems open up new areas of the aircraft design space, such as the use of distributed electric propulsion (DEP). In this approach, electric motors are placed in many different locations to achieve increased efficiency through integration of the propulsion system with the airframe. Under a project called Scalable Convergent Electric Propulsion Technology Operations Research (SCEPTOR), NASA is designing a flight demonstrator aircraft that employs many "high-lift propellers" distributed upstream of the wing leading edge and two cruise propellers (one at each wingtip). As the high-lift propellers are operational at low flight speeds (take-off/approach flight conditions), the impact of the DEP configuration on the aircraft noise signature is also an important design consideration. This paper describes efforts toward the development of a mulitfidelity aerodynamic and acoustic methodology for DEP high-lift propeller aeroacoustic modeling. Specifically, the PAS, OVERFLOW 2, and FUN3D codes are used to predict the aerodynamic performance of a baseline high-lift propeller blade set. Blade surface pressure results from the aerodynamic predictions are then used with PSU-WOPWOP and the F1A module of the NASA second generation Aircraft NOise Prediction Program to predict the isolated high-lift propeller noise source. Comparisons of predictions indicate that general trends related to angle of attack effects at the blade passage frequency are captured well with the various codes. Results for higher harmonics of the blade passage frequency appear consistent for the CFD based methods. Conversely, evidence of the need for a study of the effects of increased azimuthal grid resolution on the PAS based results is indicated and will be pursued in future work. Overall, the results indicate that the computational approach is acceptable for fundamental assessment of low-noise highlift propeller designs. The extent to which the various approaches may be used in a complementary manner will be further established as measured data becomes available for validation. Ultimately, it is anticipated that this combined approach may be used to provide realistic incident source fields for acoustic shielding/scattering studies on various aircraft configurations.
\end{abstract}

\section{Nomenclature}

Symbols:

$\alpha$

$\theta$

$\phi$ revolutions per second

$$
\text { propeller diameter }
$$

advance ratio $=V_{f} / n D$

forward flight speed

* Senior Research Scientist, Research Directorate, Structural Acoustics Branch, AIAA Associate Fellow

${ }^{\dagger}$ Senior Research Scientist, Research Directorate, Computational Aerosciences Branch, AIAA Associate Fellow

${ }^{\ddagger}$ Senior Research Scientist, Research Directorate, Computational Aerosciences Branch, AIAA Associate Fellow

${ }^{\S}$ Research Scientist, Research Directorate, Computational Aerosciences Branch, AIAA Member 
Acronyms:

$\begin{array}{ll}\text { BPF } & \text { blade passage frequency } \\ \text { F3D } & \text { FUN3D } \\ \text { OVF } & \text { OVERFLOW 2 } \\ \text { PAS } & \text { Propeller Analysis System } \\ \text { RPM } & \text { revolutions per minute }\end{array}$

\section{Introduction}

Over the past several years, the use of electric propulsion technologies within aircraft design has received increased attention. The characteristics of electric propulsion systems open up new areas of the aircraft design space, such as the use of distributed electric propulsion (DEP). In this approach, electric motors are placed in many different locations to achieve increased efficiency through integration of the propulsion system with the airframe. Under a project called Scalable Convergent Electric Propulsion Technology Operations Research (SCEPTOR), ${ }^{1 / 3}$ NASA is designing a flight demonstrator aircraft similar to that shown in Figure 1 The configuration employs many "high-lift propellers" distributed upstream of the wing leading edge and two cruise propellers (one at each wingtip). The highlift propellers are designed to increase the dynamic pressure over the sections of the wing in the propeller slipstreams, thereby increasing the total lift. As they are meant to act similarly to conventional high-lift devices, these propellers only operate at low flight speeds. At higher flight speeds, the two cruise propellers provide all the propulsive thrust for the aircraft and the high-lift propellers are folded and stowed against the nacelles to reduce drag.

As the high-lift propellers are operational at low flight speeds (take-off/approach flight conditions), the impact of the DEP configuration on the aircraft noise signature is also an important design consideration. This paper describes an initial study of the source noise produced by the isolated high-lift propellers and sets the stage for the prediction of installation effects. The baseline design is a propeller concept used in initial DEP testing ${ }^{4 / 5}$ and is representative of subsequent high-lift propeller designs. The propeller configuration and operating conditions of interest are first presented in Section II This is followed by a discussion of the aerodynamic and acoustic prediction codes in Sections III] and IV] Comparison of predicted results are then presented in Section V] Finally, concluding remarks regarding some of the more significant results and further areas of interest are presented in Section VI.

\section{Propeller Configuration}

The high-lift propeller considered in this study is the five-bladed design by Stoll ${ }^{45}$ shown in Figure 2 As mentioned above, this propeller design has been used in previous DEP studies 45 and is representative of initial high-lift propeller designs. In addition, the design is scheduled to be tested in the NASA Langley Low Speed Aeroacoustic Wind Tunnel (LSAWT) ${ }^{6}$ and measured performance and acoustic data will be available for subsequent validation. The propeller diameter is $D=0.44 \mathrm{~m}(1.44 \mathrm{ft})$ and the baseline forward flight speed, $V_{f}=31.4 \mathrm{~m} / \mathrm{s}(103.0 \mathrm{ft} / \mathrm{s})$, and propeller RPM (5866) chosen for this study correspond to takeoff conditions. Predictions are performed at angles of attack, $\alpha$, ranging from $0^{\circ}-9^{\circ}$ to investigate angle of attack effects. In preparation for comparison with measured data, additional forward flight speeds and propeller RPM at $\alpha=0^{\circ}$ are also briefly considered.

The observer locations for acoustic predictions are shown in Figure 2 Sideline directivity is captured on an arc of radius $3.54 \mathrm{~m}(11.60 \mathrm{ft})$ centered on the propeller axis and propeller plane of rotation. Sideline angles, $\theta$, ranging from $0^{\circ}-180^{\circ}$ are included, with $\theta=0^{\circ}$ pointing in the upstream (forward flight) direction and $\theta=180^{\circ}$ pointing in the downstream (aft) direction. A ring (radius $3.54 \mathrm{~m}(11.60 \mathrm{ft})$ ) of observers centered on the propeller axis in the propeller plane of rotation encompassing the full range of azimuthal angles $\left(0^{\circ} \leq \phi \leq 360^{\circ}\right)$ is also included to study angle of attack effects. Looking downstream (aft) into the propeller, $0 \leq \phi \leq 180^{\circ}$ represents the upper half of the propeller disc and $180 \leq \phi \leq 360^{\circ}$ represents the lower half of the propeller disc.

\section{Aerodynamic Predictions}

Both a structured and unstructured computational fluid dynamics (CFD) code, as well as a blade element approach are used in this study to predict propeller aerodynamic performance and obtain blade loading information. These codes are described in detail in the cited references, so only background information on the various codes is provided herein. 


\section{A. Propeller Analysis System (PAS)}

The NASA Aircraft Noise Prediction Program (ANOPP) Propeller Analysis System ${ }^{7 / 8}$ is a set of computational modules for predicting the aerodynamics, performance, and noise of propellers. Classical aerodynamic theory is used to find the surface pressures and frictional stresses on the blade surfaces. Specifically, propeller blade geometry is given in terms of blade surface coordinates derived from a Joukowski transform of the blade sections. Potential flow around the blade sections is computed by Theodorsen's method by using the Kutta condition to fix the circulation. Blade boundary layers are computed by using the Holstein-Bohlen method in the laminar region and the TrucKenbrodt method in the turbulent region.

\section{B. OVERFLOW 2 (OVF)}

OVERFLOW $2^{9-12}$ is a three-dimensional time-marching implicit Navier-Stokes code that uses structured overset grid systems. Several different inviscid flux algorithms and implicit solution algorithms are included and the code has options for thin layer or full viscous terms. A wide variety of boundary conditions are available, as well as algebraic, one-equation, and two-equation turbulence models. Low speed preconditioning is also available for several of the inviscid flux algorithms and solution algorithms in the code. The code also supports bodies in relative motion, and includes both a six-degree-of-freedom (6- DOF) model and a grid assembly code.

\section{FUN3D (F3D)}

The FUN3D flow solver ${ }^{13} \mid 17$ has an extensive list of options and solution mechanisms for spatial and temporal discretizations on general static or dynamic mixed-element unstructured meshes that may or may not contain overset mesh topologies. In the current study, the spatial discretization uses a finite-volume approach in which the dependent variables are stored at the vertices of mixed element meshes. Inviscid fluxes at cell interfaces are computed by using the upwind scheme of Roe $\frac{18}{18}$ and viscous fluxes are formed by using an approach that is equivalent to a central difference Galerkin procedure. The eddy viscosity is modeled by using the one-equation approach of Spalart and Allmaras 19 with the source term modification proposed by Dacles-Mariani et al ${ }^{20}$ Scalable parallelization is achieved through domain decomposition and message-passing communication.

An approximate solution of the linear system of equations that is formed within each time step is obtained through several iterations of a multicolor Gauss-Seidel point-iterative scheme. The turbulence model is integrated all the way to the wall without the use of wall functions. The turbulence model is solved separately from the mean flow equations at each time step with a time integration and a linear system solution scheme that is identical to that employed for the mean flow equations.

A dual time-stepping algorithm with subiterations is used to converge the solution within each physical timestep. For these simulations, a maximum of 20 subiterations per time-step was used. However, a temporal error controller was used to monitor the subiteration convergence history advancing to the next physical time-step when the flow residuals dropped below ten percent of the estimated temporal error. A variety of time marching schemes are available in FUN3D, including a second-order backward-differencing formulation (BDF2), and an optimized second order backward differencing formulation (BDF2OPT). The BDF2OPT scheme ${ }^{21}$ was chosen for the current application as it produces lower truncation error compared to the standard BDF2 scheme at nominally the same computational cost but with slightly increased memory usage.

\section{Acoustic Predictions}

The acoustic prediction methods used in this study are based on the FW-H equation, 22 which is a rearrangement of the exact continuity and Navier-Stokes equations into a wave equation for the density with a nonlinear forcing term. Through the application of generalized functions and a Green's function technique, the solution to the equation can be reduced to a surface and a volume integral, but the solution is often well approximated by the surface integral alone. The volume integral includes physical effects such as refraction and nonlinear steepening. When these effects are small, the FW-H surface can coincide with the solid body generating the unsteady flow. This is often referred to as an impermeable data surface. When effects such as refraction are important, the FW-H surface can be pushed out into the flow to encompass important flow gradients. In this case, the data surface is referred to as being permeable (also, penetrable or porous). Hence, the time history of the density, which is directly related to the pressure in the far-field, can be obtained at locations far from the body from a surface integral that is either close to or on the actual 
body. For permeable surfaces that are off the body, the time histories of all the flow variables are needed, but no spatial derivatives are explicitly required. For surfaces coinciding with the body, only the pressure time history is needed.

The PSU-WOPWOP (PSW) code ${ }^{[23}$ and the F1A module of NASA's second generation Aircraft NOise Prediction Program (ANOPP2) ${ }^{[24}$ both implementing Farassat's retarded-time formulation 1A of the FW-H equation, are used to calculate the propeller source noise. Both the solvers were used for the acoustic predictions at select conditions and the two codes provided nearly identical results. Therefore, only a single set of results based on the PSW predictions are presented and may be considered indicative of both acoustic prediction codes.

All acoustic predictions are based on impermeable data surfaces. In specifying the geometry and loading values for the acoustic data surfaces, the information may be considered 'constant', 'periodic', or 'aperiodic'. Information specified as 'constant' is assumed to remain unchanged for all source times. In terms of geometry, this means that the blade shapes remain unchanged as they rotate. For loading specification, the surface pressure values would remain unchanged as the blades rotate (as would be the case if the mean loading values were specified). For 'periodic' data, values are taken to change as a function of azimuthal angle. Finally, for 'aperiodic' data, values are taken to change arbitrarily as a function of time. The propeller blades are assumed rigid, with shapes taken to be the same at all speeds. Therefore, within the acoustic calculations, the geometry of the acoustic data surfaces could be considered 'constant' and rotating at the specified RPM. This meant that surface geometry for only a single CFD time step would be needed as input. Alternatively, the data surfaces could be specified as 'periodic' and the geometry for all time steps would be needed. Predictions were performed using both approaches to verify input specification and, as expected, essentially identical results were obtained. Therefore, the acoustic data surface geometry is specified as 'constant' in subsequent predictions due to the reduction in input file size. Conversely, the surface pressure loading is taken to be 'periodic' (i.e., changing as a function of azimuthal angle and repeating on a once-per-revolution basis). Specifically, time dependent surface pressure loading values for one full rotor revolution are extracted from the aerodynamic predictions solutions (after suitable convergence was reached for the CFD approaches) and used as input. For the cases utilizing the F3D and OVF loading information, acoustic predictions are based on CFD values at $1.0^{\circ}$ azimuthal resolution. However, due to issues with the Propeller Loading Module (PLD) of PAS, acoustic prediction utilizing the PAS loading are based on information at 5.0 azimuthal resolution. More specifically, specification of 361 azimuthal angles in the PAS input generated an error condition indicating insufficient dynamic storage in the Propeller Loading Module (PLD). Therefore, the number of azimuthal angles was reduced to alleviate this issue. Acoustic results for $\alpha \neq 0^{\circ}$ using the PAS loading are therefore expected to have reduced resolution for the higher harmonics of the blade passage frequency (BPF). This is an issue for future investigation regarding increased PAS azimuthal resolution, as well as the effects of decreased CFD azimuthal resolution on acoustic predictions.

\section{Results and Discussion}

Aerodynamic and acoustic results are first presented for the cases related to nominal takeoff conditions $\left(V_{f}=\right.$ $31.4 \mathrm{~m} / \mathrm{s}$ (103.0 ft/s), RPM 5866). In all cases, the blade angles are kept constant. However, for the baseline case, the blade angle used in the PAS predictions was iterated upon until predicted thrust levels closely matched the average between the F3D and OVF values. The result was a PAS blade angle that is approximately $5^{\circ}$ less than that used in the CFD predictions. Qualitative comparison of the OVF and PAS blade loads for the $\alpha=0^{\circ}$ case are shown in Figures 3 . In addition to the differences in blade loading, these figure illustrate the geometrical differences related to the various aerodynamic prediction methodologies. Whereas the OVF and F3D blade geometries include the full root and tip regions, the PAS blade geometry has truncated root and tip regions due to the input requirements of the blade element approach. Despite these differences, the PAS results appear to capture the overall pressure distribution fairly well. This is further indicated by comparisons of the thrust coefficients in Figure 5 and overall thrust levels in Table 1 . All of the predictions show a relative increase in thrust as the angle of attack is increased, with the PAS results showing a slightly larger increase at $\alpha=9^{\circ}$.

Acoustic predictions are obtained at locations corresponding to the observer arrangement shown in Figure 2 . As seen in Figure 6, only the rotor blade surfaces are included for which the required surface pressure values are provided by the aforementioned aerodynamic predictions. In addition to the blade surfaces, the OVF data surfaces contain a portion of the collar grids for each blade. The collar grids are necessary for the aerodynamic predictions and the inclusion of the small portion of the nacelle surface is assumed to have a negligible effect on the acoustic results. As mentioned above, the PAS data surfaces include truncated root and tip regions, which may affect acoustic results, particularly due to tip loading. While the separate thickness (monopole) and loading (dipole) acoustic contributions are obtained in the predictions, only the total values are presented. In an attempt to cover a range of possible metrics for prediction assessment, comparisons include the directivity for the dominant BPF tone, tonal amplitudes at BPF 
Table 1: Predicted thrust values at various angles of attack $\left(\alpha=0^{\circ}, 3^{\circ}, 6^{\circ}, 9^{\circ}\right) .\left(\mathrm{RPM}=5866, V_{f}=31 \mathrm{~m} / \mathrm{s}\right)$

\begin{tabular}{|c|c|c|c|}
\hline Angle of Attack, $\alpha$ & $\begin{array}{c}\text { OVF Thrust } \\
N\left(\mathrm{lb}_{\mathrm{f}}\right)\end{array}$ & $\begin{array}{c}\text { F3D Thrust } \\
N\left(\mathrm{lb}_{\mathrm{f}}\right)\end{array}$ & $\begin{array}{c}\text { PAS Thrust } \\
N\left(\mathrm{lb}_{\mathrm{f}}\right)\end{array}$ \\
\hline \hline $0^{\circ}$ & $161.5(36.3)$ & $156.1(35.1)$ & $158.4(35.6)$ \\
\hline $3^{\circ}$ & $162.0(36.4)$ & $156.1(35.1)$ & $160.6(36.1)$ \\
\hline $6^{\circ}$ & $162.8(36.6)$ & $157.0(35.3)$ & $163.7(36.8)$ \\
\hline $9^{\circ}$ & $164.1(36.9)$ & $158.4(35.6)$ & $167.3(37.6)$ \\
\hline
\end{tabular}

and harmonics, and noise variation for $\alpha \neq 0^{\circ}$ cases.

Figure 7 shows the predicted sound pressure level (SPL) as a function of sideline angle for the BPF and $2 \mathrm{BPF}$ tones at the $\alpha=0^{\circ}$ case. The BPF predictions using all three blade loadings compare very well. There are some discrepancies at large forward and aft locations, however, these occur at very low SPL levels that are well below the maximum value. Comparisons for $2 \mathrm{BPF}$ are not as favorable. The CFD based predictions compare fairly well over sideline angles from $30^{\circ}-160^{\circ}$, with discrepancies near the rotation axis. The PAS based predictions are below the other results over the full range of sideline angles, with some improvement near the plane of rotation. To provide an initial indication of angle of attack effects, similar predictions for the $\alpha=9^{\circ}$ case are shown in Figure 8 The relative comparisons are similar to the $\alpha=0^{\circ}$ case. However, all of the predictions indicate a general increase in level for forward and aft observer angles as a result of the increased angle of attack. This behavior will become more evident when the predictions for various azimuthal locations are presented.

In addition to directivity patterns, predictions of tone levels at BPF-5BPF are presented in Figure 9 In this figure, the dashed vertical lines indicate frequencies corresponding to BPF and higher harmonics. At each frequency, the symbols are offset to delineate predictions at increasing angles of attack $\left(\alpha=0^{\circ}, 3^{\circ}, 6^{\circ}, 9^{\circ}\right)$ progressing from left to right. The BPF predictions are very consistent across the range of observer angles, showing a general increase as the angle of attack increases. The same behavior generally holds true for the CFD based predictions over the range of frequencies. However, with the exception of 2BPF at $\alpha=0^{\circ}$ and $\theta=90^{\circ}$, the PAS based results underpredict tone levels for the BPF harmonics. As alluded to earlier, some of the discrepancies in the PAS predictions for $\alpha \neq 0^{\circ}$ cases may be due to the lack of azimuthal resolution in the aerodynamic predictions, which is a point for future study.

To further investigate angle of attack effects, results for the ring of observers centered on the propeller axis in the propeller plane of rotation (see Figure 2 and Section III) are presented in Figure 10 . Here, the change in BPF tone levels (relative to $\left.\alpha=0^{\circ}\right)$ are presented for three angles of attack $\left(\alpha=3^{\circ}, 6^{\circ}\right.$, and $\left.9^{\circ}\right)$ as a function of azimuthal observer angle. The predictions show the BPF sound field (which is azimuthally symmetric at $\alpha=0^{\circ}$ ) is decreased in the upper half of the propeller disc $\left(0^{\circ} \leq \phi \leq 180^{\circ}\right)$ and increased in lower half of the propeller disc $\left(180^{\circ} \leq \phi \leq 360^{\circ}\right)$. As with previous results, the CFD based acoustic predictions are very consistent. The PAS based predictions show the same behavior, but with diminished levels. Again, this may be the result of decreased azimuthal order in the aerodynamic predictions and will be investigated further. However, the general trends are captured, as the change in level is more pronounced as the angle of attack increases. This matches behavior discussed by Mani ${ }^{25}$ and measured by Block, ${ }^{[26}$ and demonstrates the capability of the combined aerodynamic and acoustic tools to predict such effects at the blade passage frequency.

In preparation for comparison with performance and acoustic measurements to be performed in the NASA Langley Low Speed Aeroacoustic Wind Tunnel (LSAWT), ${ }^{6}$ additional forward flight speeds and propeller RPM at $\alpha=0^{\circ}$ are also briefly considered. These cases are meant to cover a range of possible test conditions and therefore, as seen in Table 2, entail a range of forward flight speeds and RPM values. Note that only OVF and PAS loading predictions are currently available for these additional conditions. However, the $V_{f}=31.4 \mathrm{~m} / \mathrm{s}, \mathrm{RPM}=5866$ case is the same as that considered previously and the blade angles were kept constant. As with previous cases, there is reasonable comparison in the thrust values as is also shown in the thrust coefficient comparisons in Figure 11. The discrepancy increases at the highest forward flight condition. However, this may be expected at the larger advance ratio where propeller efficiency is decreasing rapidly and separated flow may be present.

Predicted sound pressure levels (SPL) at BPF as a function of sideline angle for the three additional cases are shown in Figure 12 The comparison between the OVF and PAS based predictions are similar to previous cases. However, there is a clear change in the directivity pattern as the advance ratio increases. Correspondingly, the discrepancy between the two predictions increases, possibly due in part to increasingly complex flow about the blades that is not captured by the blade element approach. However, the general trends at the blade passage frequency are again 
Table 2: Predicted thrust values at zero angle of attack $\left(\alpha=0^{\circ}\right)$.

\begin{tabular}{|c|c|c|c|c|}
\hline $\begin{array}{c}V_{f} \\
\mathrm{~m} / \mathrm{s}(\mathrm{ft} / \mathrm{s})\end{array}$ & RPM & Advance Ratio, $J$ & $\begin{array}{c}\text { OVF Thrust } \\
N\left(\mathrm{~b}_{\mathrm{f}}\right)\end{array}$ & $\begin{array}{c}\text { PAS Thrust } \\
N\left(\mathrm{lb}_{\mathrm{f}}\right)\end{array}$ \\
\hline \hline $20(65.6)$ & 5866 & 0.46 & $199.3(44.8)$ & $219.3(49.3)$ \\
\hline $31.4(103.0)$ & 5866 & 0.72 & $161.5(36.3)$ & $158.4(35.6)$ \\
\hline $40(131.2)$ & 5866 & 0.92 & $128.6(28.9)$ & $105.9(23.8)$ \\
\hline $42(137.8)$ & 4800 & 1.18 & $52.5(11.8)$ & $18.2(4.1)$ \\
\hline
\end{tabular}

captured fairly well with the PAS based blade loading and the extent to which the two approaches may be used in a complementary manner may be further established as measured data becomes available for validation.

\section{Concluding Remarks}

This paper describes efforts toward the development of a mulitfidelity aerodynamic and acoustic methodology for DEP high-lift propeller aeroacoustic modeling. Specifically, the PAS, OVERFLOW 2, and FUN3D codes are used to predict the aerodynamic performance of a baseline high-lift propeller blade set. Blade surface pressure results from the aerodynamic predictions are then used with PSU-WOPWOP and the F1A module of the NASA second generation Aircraft NOise Prediction Program to predict the isolated high-left propeller noise source. Comparisons of predictions indicate that general trends related to angle of attack effects at the blade passage frequency are captured well with the various codes. Results for higher harmonics of the blade passage frequency appear consistent for the CFD based methods. Conversely, evidence of the need for a study of the effects of increased azimuthal grid resolution on the PAS based results is indicated and will be pursued in future work. Overall, the comparison between the results suggest that the mulitfidelity aerodynamic and acoustic methodology is acceptable for fundamental assessment of low-noise highlift propeller designs. The extent to which the various approaches may be used in a complementary manner will be further established as measured data becomes available for validation. Ultimately, it is anticipated that this combined approach may also be used to provide realistic incident source fields for acoustic shielding/scattering studies on various aircraft configurations.

\section{Acknowledgments}

This research was funded by the NASA Advanced Air Vehicles Program (AAVP).

\section{References}

${ }^{1}$ Borer, N. K., Patterson, M. D., Viken, J. K., Moore, M. D., Clarke, S., Redifer, M. E., Christie, R. J., Stoll, A. M., Dubois, A., Bevirt, J., Gibson, A. R., Foster, T. J., and Osterkamp, P. G., "Design and Performance of the NASA SCEPTOR Distributed Electric Propulsion Flight Demonstrator," AIAA Paper 2016-3920, AIAA, 2016.

${ }^{2}$ Patterson, M. D., Derlaga, J. M., and Borer, N. K., "High-Lift Propeller System Configuration Selection for NASA's SCEPTOR Distributed Electric Propulsion Flight Demonstrator," AIAA Paper 2016-3922, AIAA, 2016.

${ }^{3}$ Dubois, A., van der Geest, M., Bevirt, J., Clarke, S., Christie, R. J., and Borer, N. K., "Design of an Electric Propulsion System for SCEPTOR's Outboard Nacelle," AIAA Paper 2016-3925, AIAA, 2016.

${ }^{4}$ Stoll, A. M., Bevirt, J., Moore, M. D., Fredericks, W. J., and Borer, N. K., "Drag Reduction Through Distributed Electric Propulsion,” AIAA Paper 2014-2851, 2014.

${ }^{5}$ Stoll, A. M., "Comparison of CFD and Experimental Results of the LEAPTech Distributed Electric Propulsion Blown Wing," AIAA Paper 2015-3188, 2015.

${ }^{6}$ Zawodny, N. S. and Haskin, H. H., "Small Propeller and Rotor Testing Capabilities of the NASA Langley Low Speed Aeroacoustic Wind Tunnel," (submitted for publication), 23rd AIAA/CEAS Aeroacoustics Conference, Denver, CO, 2017.

${ }^{7}$ Nguyen, L. C., "The NASA Aircraft Noise Prediction Program Improved Propeller Analysis System," NASA CR 4394, 1991.

${ }^{8}$ Nguyen, L. C. and Kelly, J. J., "A Users Guide for the NASA ANOPP Propeller Analysis System,” NASA CR 4768, February 1997.

${ }^{9}$ Nichols, R. H. and Buning, P. G., "User's Manual for OVERFLOW 2.2," http://overflow.larc.nasa.gov/home/users-manual-for-overflow-2-2/, (Version 2.2k, March 2015).

${ }^{10}$ Nichols, R. H., Tramel, R. W., and Buning, P. G., "Solver and Turbulence Model Upgrades to OVERFLOW2 for Unsteady and High-Speed Applications," AIAA Paper 2006-2824, 2006.

${ }^{11}$ Buning, P. G., "CFD Approaches for Simulation of Wing-Body Stage Separation,” AIAA Paper 2004-4838. 
${ }^{12}$ Boyd, D. D., "HART-II Acoustic Predictions using a Coupled CFD / CSD Method," American Helicopter Society 65th Annual Forum, Grapevine, TX, 2009.

13“FUN3D User Manual," http://fun3d.larc.nasa.gov.

${ }^{14}$ Anderson, W. K. and Bonhaus, D. L., "An Implicit Upwind Algorithm for Computing Turbulent Flows on Unstructured Grids," Computers and Fluids, Vol. 23, No. 1, 1994, pp. 1-21.

${ }^{15}$ Anderson, W. K., Rausch, R. D., and Bonhaus, D. L., "Implicit/Multigrid Algorithms for Incompressible Turbulent Flows on Unstructured Grids," Journal of Computational Physics, Vol. 128, No. 2, 1996, pp. 391-408.

${ }^{16}$ Nielsen, E. J., Aerodynamic Design Sensitivities on an Unstructured Mesh Using the Navier-Stokes Equations and a Discrete Adjoint Formulation, Ph.D. thesis, Virginia Polytechnic Institute and State University, Department of Aerospace and Ocean Engineering, December 1998.

${ }^{17}$ Biedron, R. T. and Thomas, J. L., "Recent Enhancements to the FUN3D Flow Solver for Moving-Mesh Applications," AIAA Paper 20091360, 2009.

${ }^{18}$ Roe, P. L., “Approximate Riemann Solvers, Parameter Vectors, and Difference Schemes," Journal of Computational Physics, Vol. 43, No. 2 , 1981, pp. 357-372.

${ }^{19}$ Spalart, P. R. and Allmaras, S. R., “A One-Equation Turbulence Model for Aerodynamic Flows,” AIAA Paper 92-0439, 1992.

${ }^{20}$ Dacles-Mariani, J., Zilliac, G., Chow, J. S., and Bradshaw, P., "Numerical/Experimental Study of a Wingtip Vortex in the Near Field," AIAA Journal, Vol. 33, No. 9, 1995, pp. 1561-1568.

${ }^{21}$ Vatsa, V., Carpenter, M., and Lockard, D., "Re-evaluation of an Optimized Second Order Backward Difference (BDF2OPT) Scheme for Unsteady Flow Applications,” AIAA Paper 2010-0122, 2010.

${ }^{22}$ Williams, J. E. F. and Hawkings, D. L., "Sound Generation by Turbulence and Surfaces in Arbitrary Motion," Philosophical Transactions of the Royal Society of London A, Vol. 342, 1969, pp. 264-321.

${ }^{23}$ Brentner, K. S., Lopes, L. V., Chen, H. N., and Horn, J. F., "Near Real-Time Simulation of Rotorcraft Acoustics and Flight Dynamics," AIAA Journal, Vol. 42, No. 2, March-April 2005, pp. 347-355.

${ }^{24}$ Lopes, L. V. and Burley, C. L., "Design of the Next Generation Aircraft NOise Prediction Program: ANOPP2,” AIAA Paper 2011-2854, 2011.

${ }^{25}$ Mani, R., "The Radiation of Sound from a Propeller at Angle of Attack," Proceedings of the Royal Society of London A, Vol. 431, 1990, pp. 203-218.

${ }^{26}$ Block, P., "The Effects of Installation on Single- and Counter-Rotation Propeller Noise," AIAA Paper 84-2263, AIAA, 1984.

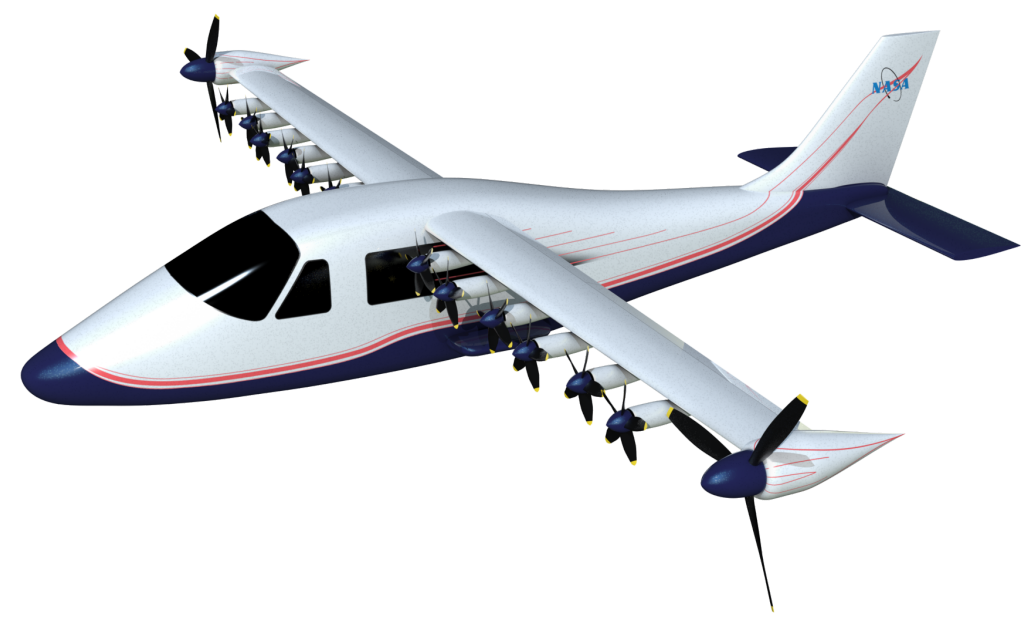

Figure 1: NASA rendering of potential SCEPTOR configuration. $1+[-3$ 


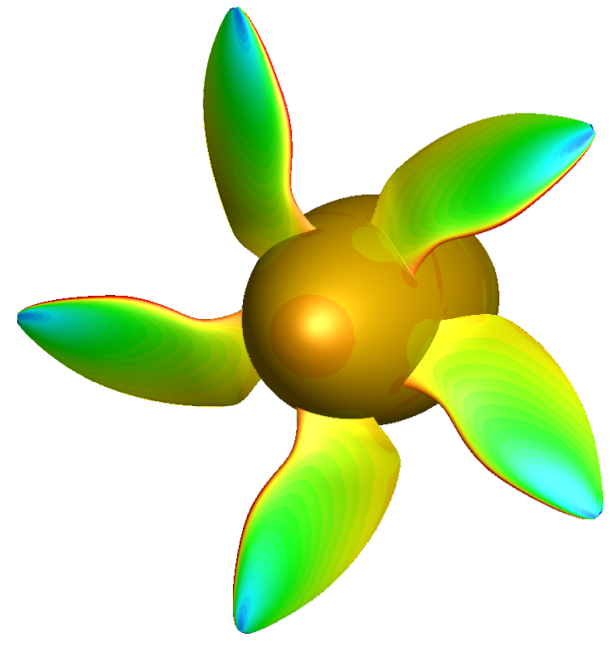

(a) High-lift propeller desigr 4

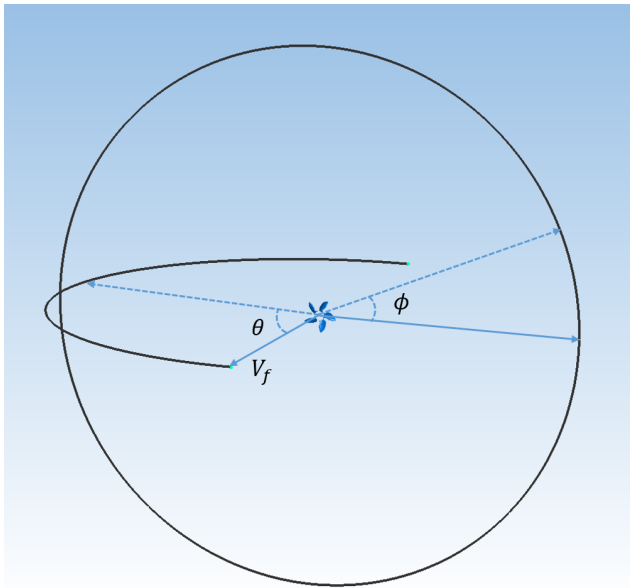

(b) Sideline, $\theta$, and azimuthal, $\phi$, observer angles.

Figure 2: High-lift propeller and associated observer locations for acoustic predictions. The forward flight vector, $V_{f}$, corresponds to $\theta=0^{\circ}$ and the ring of observers is located in the plane of rotation of the propeller.

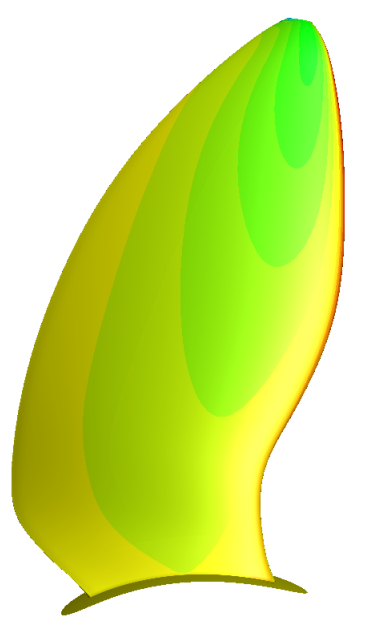

(a) OVF

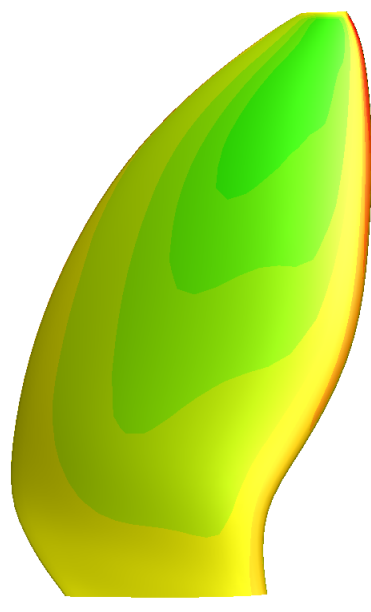

(b) PAS

Figure 3: Qualitative comparison of OVF and PAS suction side blade loading. $\left(\alpha=0^{\circ}, \mathrm{RPM}=5866, V_{f}=31 \mathrm{~m} / \mathrm{s}\right)$ 


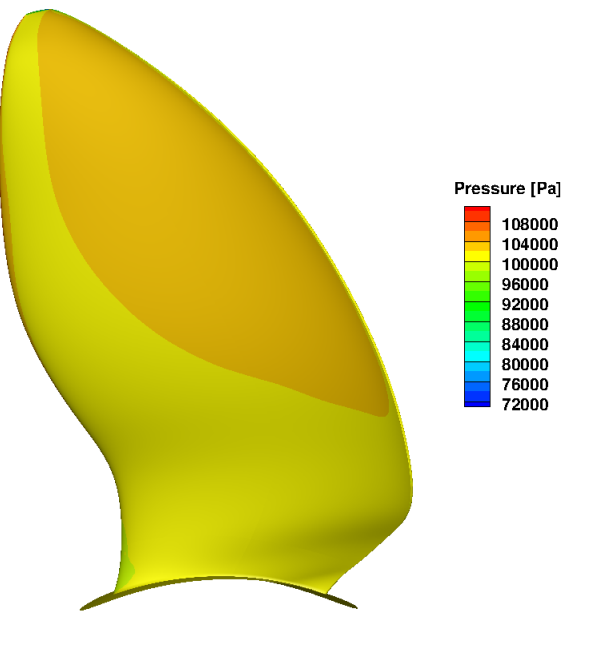

(a) OVF

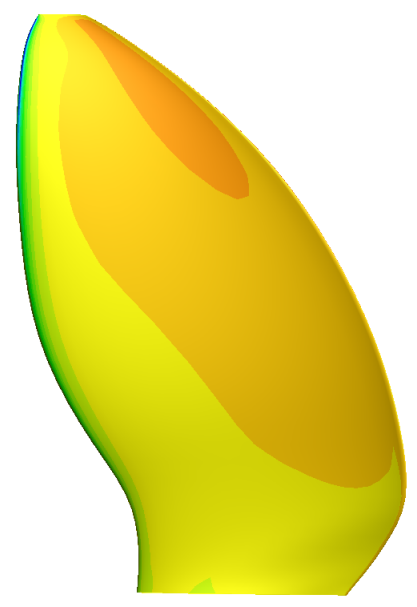

(b) PAS

Figure 4: Qualitative comparison of OVF and PAS pressure side blade loading. $\left(\alpha=0^{\circ}, \mathrm{RPM}=5866, V_{f}=31 \mathrm{~m} / \mathrm{s}\right)$

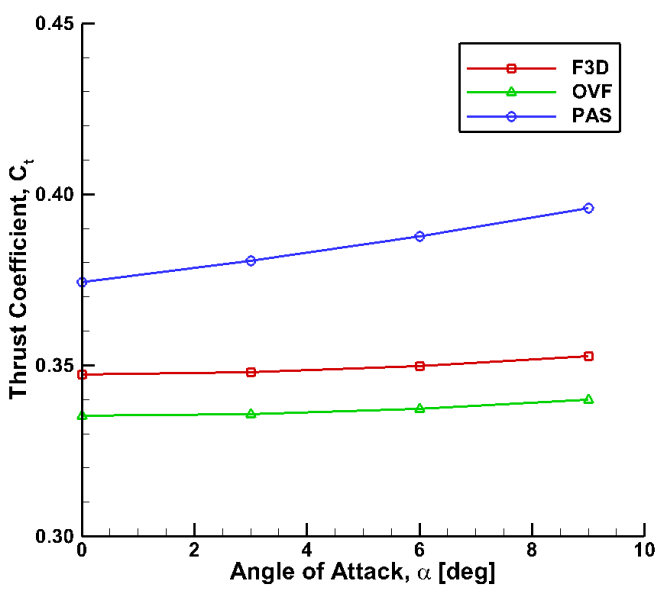

Figure 5: Predicted thrust coefficients at various angles of attack $\left(\alpha=0^{\circ}, 3^{\circ}, 6^{\circ}, 9^{\circ}\right)$. (RPM=5866, $\left.V_{f}=31 \mathrm{~m} / \mathrm{s}\right)$ 


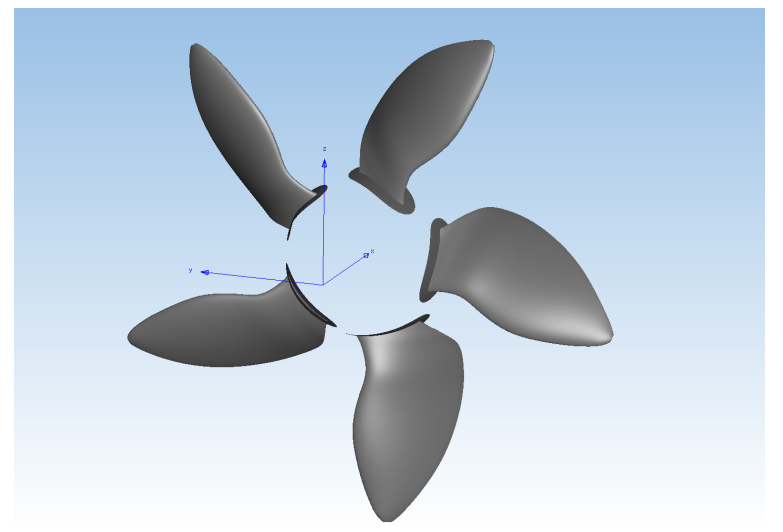

(a) OVF

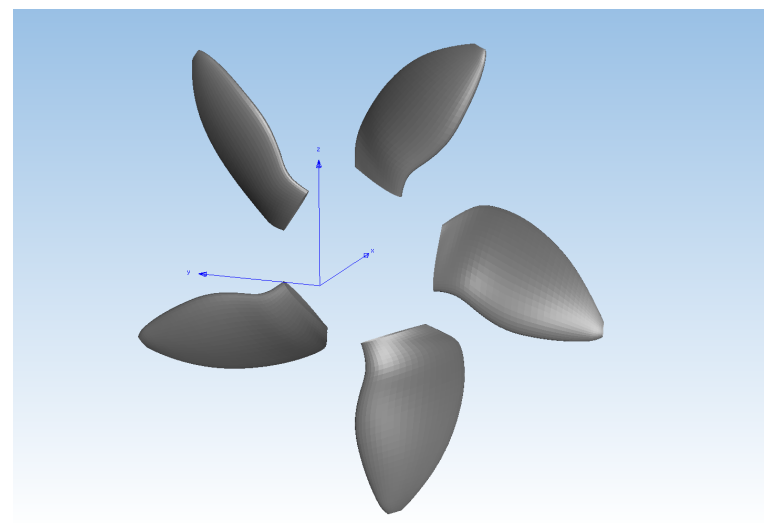

(b) PAS

Figure 6: Representative impermeable data surfaces used in acoustic predictions.

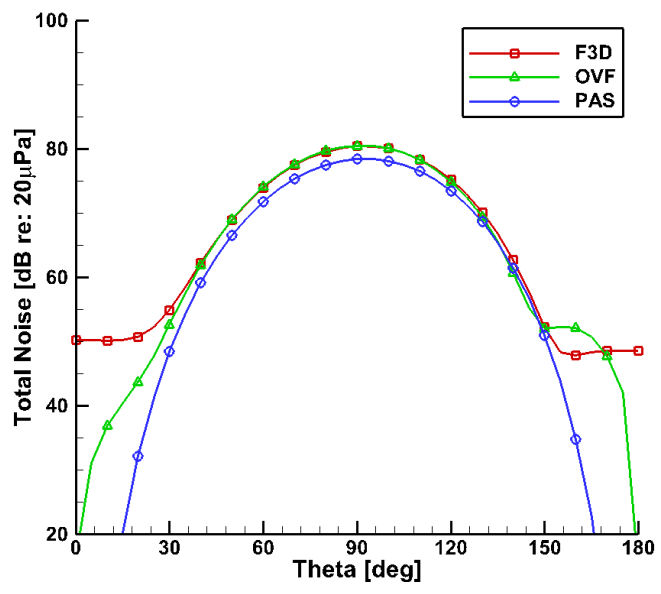

(a) BPF: $488 \mathrm{~Hz}$

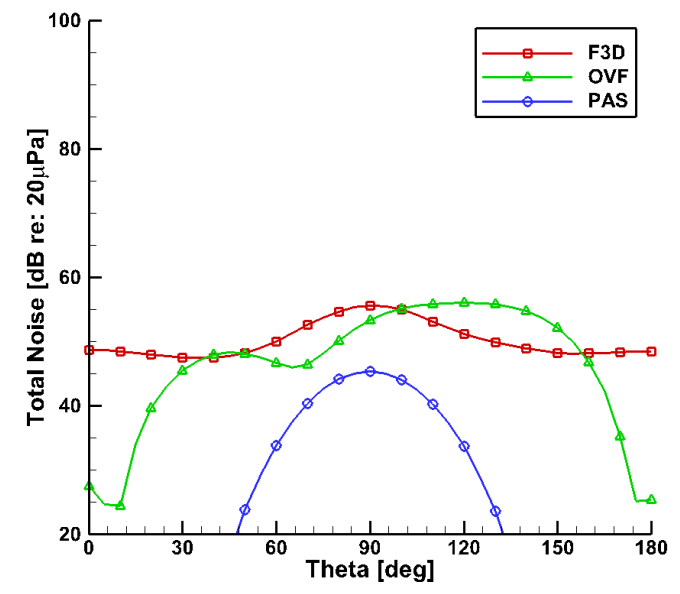

(b) 2BPF: 976

Figure 7: Comparison of predicted SPL levels as a function of sideline observer angle, $\theta$ for the propeller at $\alpha=0^{\circ}$. $\left(\mathrm{RPM}=5866, V_{f}=31 \mathrm{~m} / \mathrm{s}\right)$ 


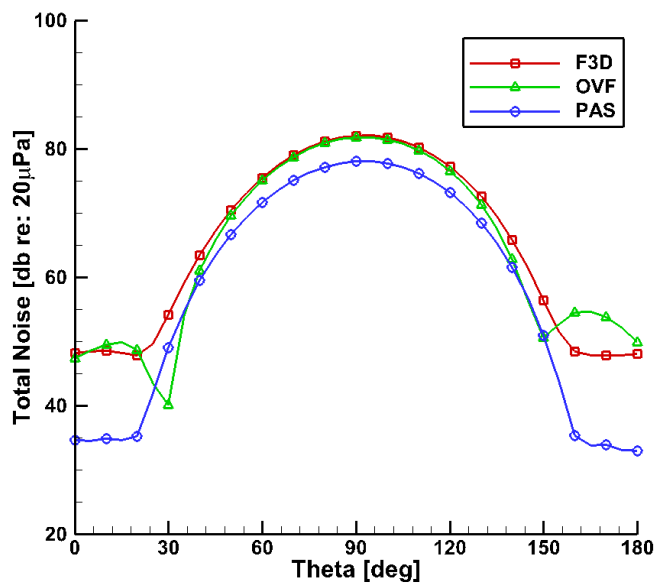

(a) BPF: $488 \mathrm{~Hz}$

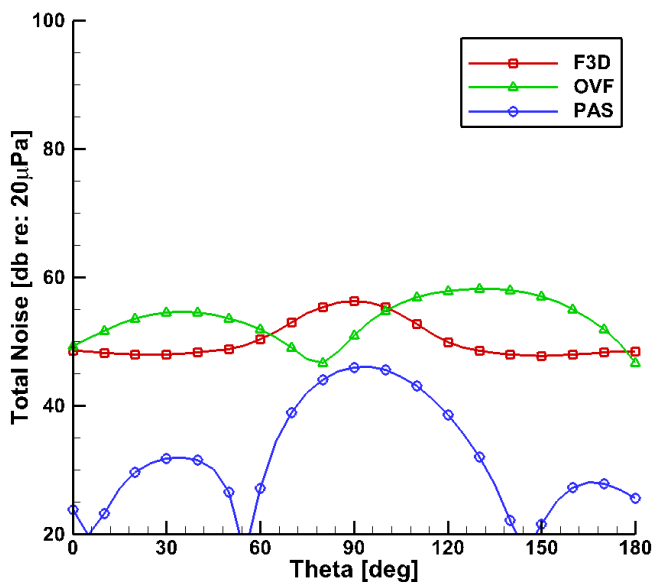

(b) 2BPF: 976

Figure 8: Comparison of predicted SPL levels as a function of sideline observer angle, $\theta$ for the propeller at $\alpha=9^{\circ}$. $\left(\mathrm{RPM}=5866, V_{f}=31 \mathrm{~m} / \mathrm{s}\right)$ 


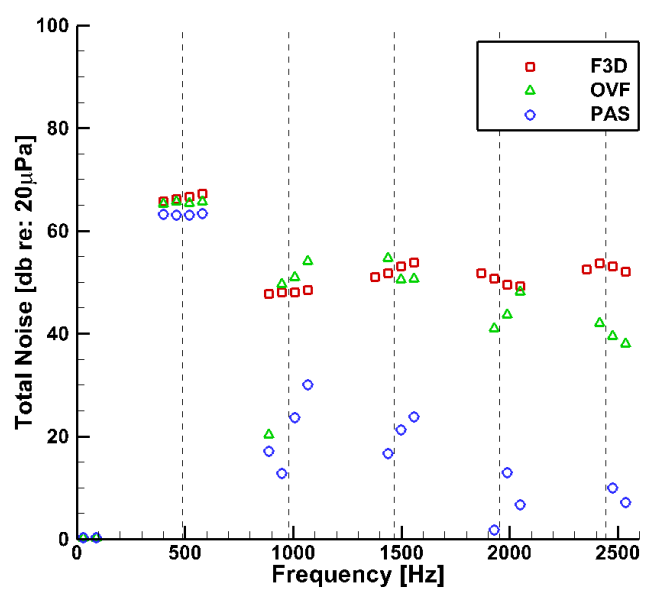

(a) $\theta=45^{\circ}$

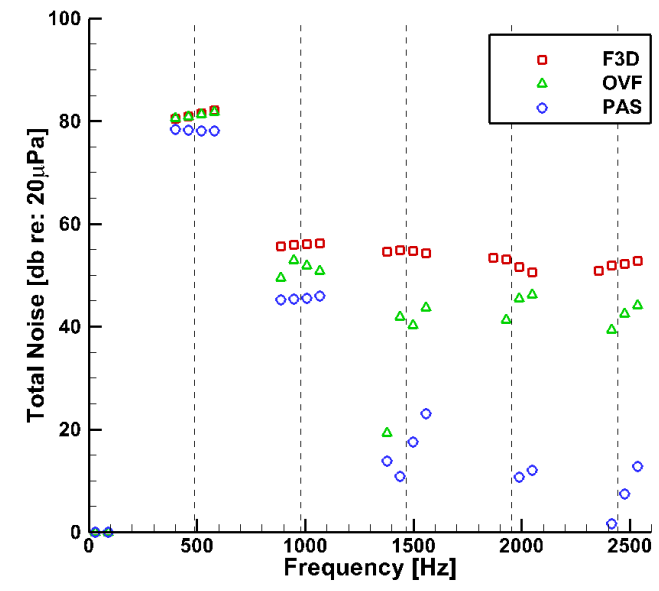

(b) $\theta=90^{\circ}$

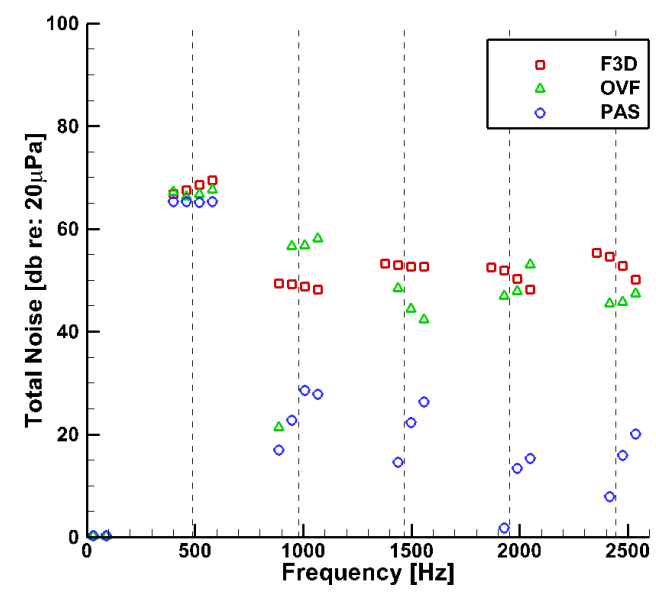

(c) $\theta=135^{\circ}$

Figure 9: Comparison of predicted noise levels (BPF and harmonics) at various sideline observer locations for several propeller angles of attack $\left(\alpha=0^{\circ}, 3^{\circ}, 6^{\circ}, 9^{\circ}\right)$. Dashed vertical lines indicate BPF and harmonics. Symbols are offset for visual clarity and are presented in increasing angle of attack from left to right. (RPM=5866, $V_{f}=31 \mathrm{~m} / \mathrm{s}$ ) 


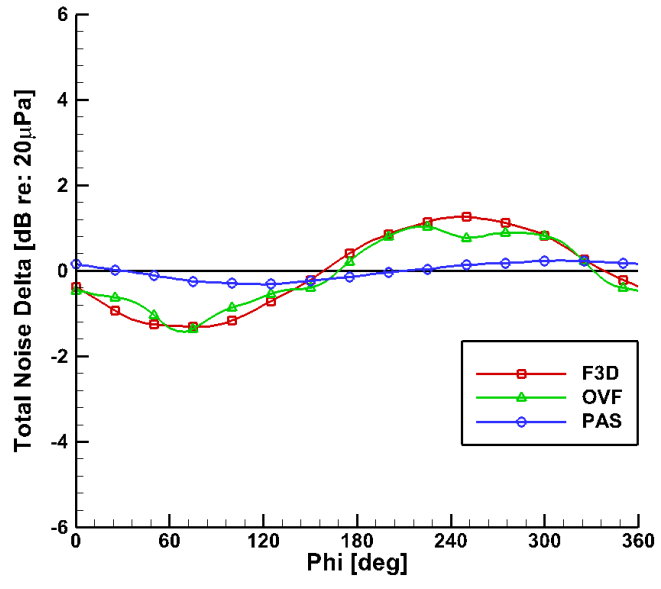

(a) $\alpha=3^{\circ}$

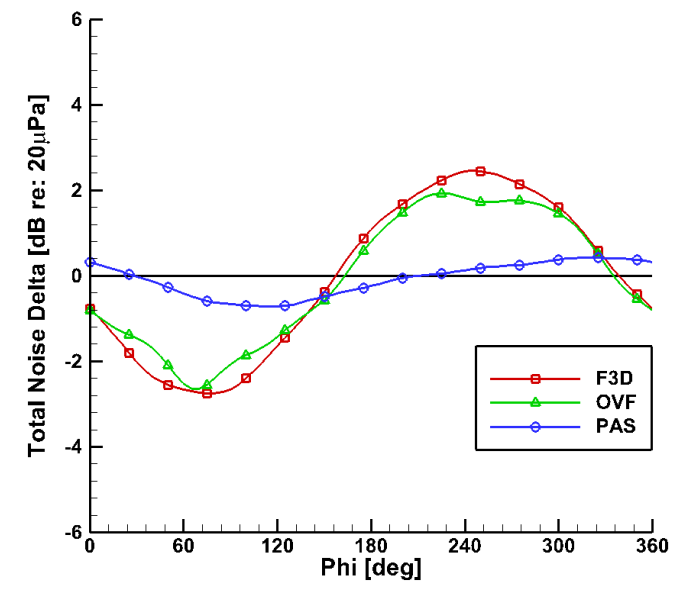

(b) $\alpha=6^{\circ}$

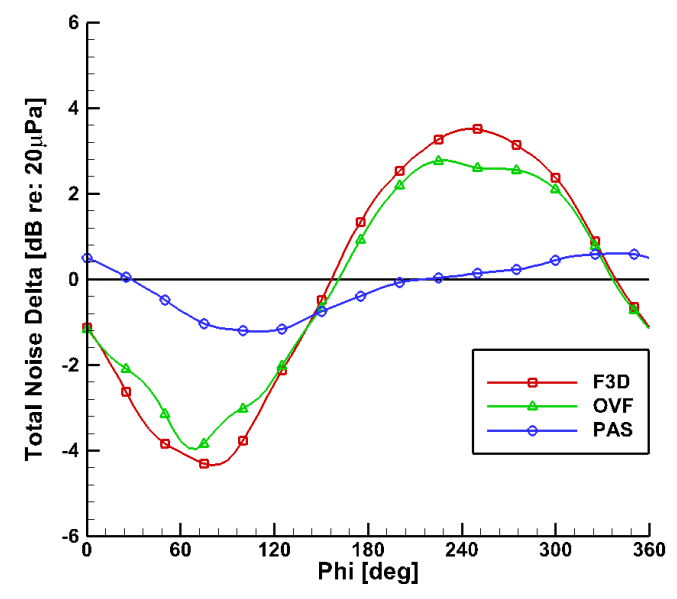

(c) $\alpha=9^{\circ}$

Figure 10: Increase/Decrease of noise due to positive angle of attack (relative to $\alpha=0^{\circ}$ ) as a function of azimuthal angle. (RPM=5866, $\left.V_{f}=31 \mathrm{~m} / \mathrm{s}\right)$ 


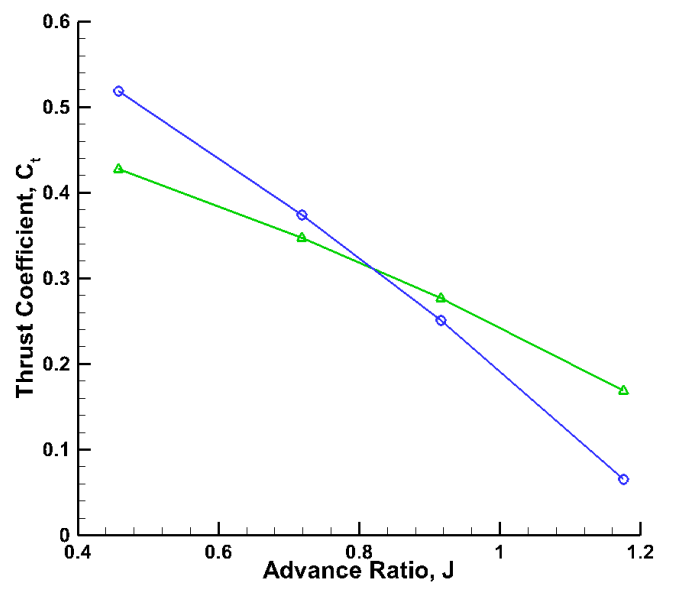

Figure 11: Predicted thrust coefficients at zero angle of attack $\left(\alpha=0^{\circ}\right)$. 


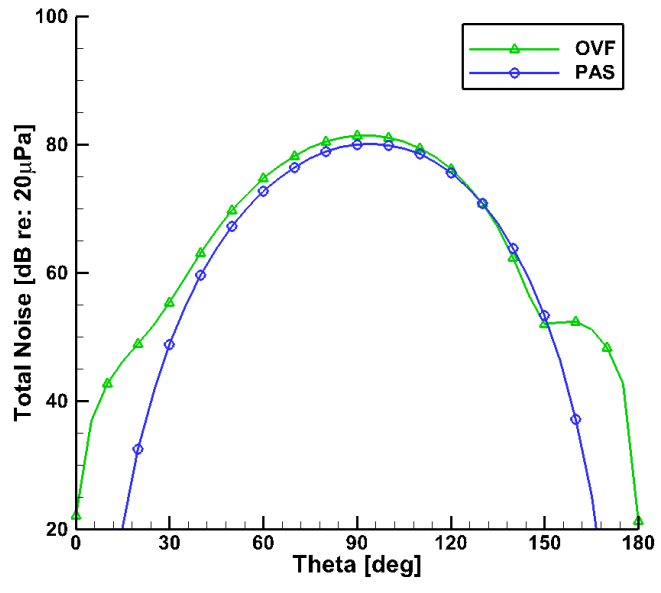

(a) BPF: $488 \mathrm{~Hz}\left(\mathrm{RPM}=5866, V_{f}=20 \mathrm{~m} / \mathrm{s}\right)$

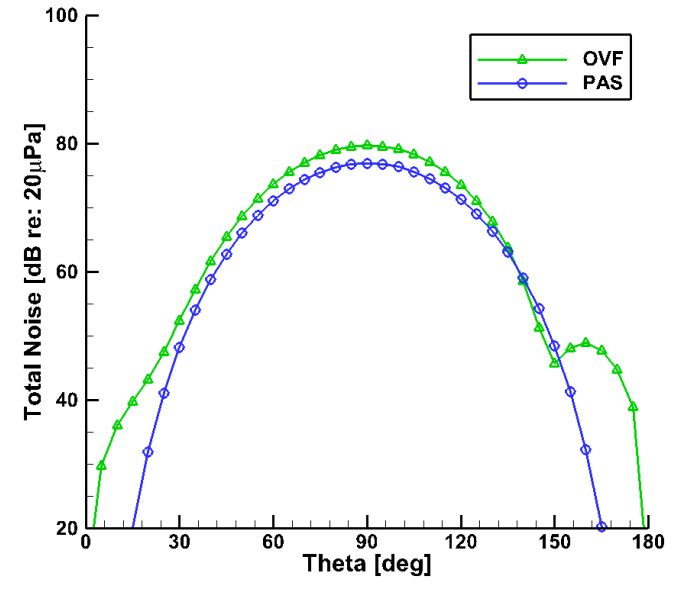

(b) BPF: $488 \mathrm{~Hz}\left(\mathrm{RPM}=5866, V_{f}=40 \mathrm{~m} / \mathrm{s}\right)$

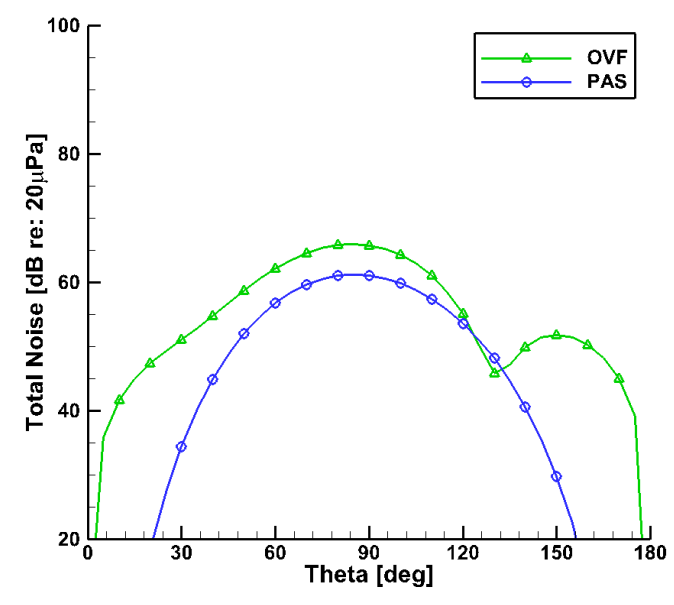

(c) BPF: $400 \mathrm{~Hz}\left(\mathrm{RPM}=4800, V_{f}=42 \mathrm{~m} / \mathrm{s}\right)$

Figure 12: Comparison of predicted SPL levels at the blade passage frequency as a function of sideline observer angle, $\theta$ for the propeller at $\alpha=0^{\circ}$. 